\title{
Contrasting Observation and Transect-Based Models of Cattle Distribution on Lincoln National Forest, New Mexico
}

\author{
Heather Halbritter ${ }^{1}$ and Louis C. Bender ${ }^{2}$ \\ Authors are ${ }^{1}$ Graduate Research Assistant, Department of Fisheries and Wildlife, New Mexico State University, Las Cruces, NM 88003, USA; and \\ ${ }^{2}$ Research Scientist (Wildlife), Extension Animal Sciences and Natural Resources, New Mexico State University, PO Box 30003 MSC $3 A$ E, Las Cruces, \\ NM 88003, USA.
}

\begin{abstract}
Perceptions of cattle distribution and resource conflicts are often based upon qualitative observations of cattle by managers or the general public. Such information on cattle presence and inferred habitat preferences may not reflect true habitat correlates of cattle because observations do not include any sampling design. We documented cattle presence and used presence data to model distribution of cattle with respect to landscape features on the Lincoln National Forest (LNF) of south-central New Mexico, an area of conflict with regard to cattle herbivory. We recorded cattle presence both from visual observations of cattle while conducting other research activities and from randomized pellet-group transects during the spring-autumn period when cattle grazed the highelevation habitats. Distribution of cattle differed for several habitat variables between datasets, although distribution models from both datasets indicated that elevation, slope, distance to water and roads, and vegetation cover type most influenced cattle presence. Cattle presence was associated with a variety of cover types, and cattle were generally within $500 \mathrm{~m}$ of water and on slopes of $<15-$ $20 \%$. Observation-based models showed positive associations with open cover types, including the strongest positive association with montane meadows, the area of conflict in LNF. In contrast, transect-based models showed positive associations with more cover types (11) than did observation-based (6). Observation-based models also showed higher association with areas closer to roads. Inferred habitat preferences based on casual observations of cattle may not accurately reflect true distribution or use, as transectbased models predicted much broader distribution throughout LNF and higher overall probabilities of cattle presence. Because cattle distribution included many other vegetation cover types in addition to montane meadows, management to enhance positive correlates of cattle distribution on LNF may be useful to alter cattle distribution away from areas of perceived conflict.
\end{abstract}

\section{Resumen}

Percepciones sobre la distribución del ganado y el conflicto de recursos se basan frecuentemente en observaciones cualitativas de los manejadores del ganado y el público en general. Esta información, sobre la presencia del ganado y la suposición de la preferencia de hábitat, tal vez no refleja la verdadera correlación entre hábitat y ganado por que las observaciones no incluyen un diseño de muestreo. Documentamos la presencia del ganado y usamos estos datos para modelar la distribución del mismo con respecto a las características del paisaje en Lincoln National Forest (LNF) en la parte Sur-Central de Nuevo México, en un área de conflictos que involucra el ganado. Se registro la presencia del ganado con observaciones visuales mientras se realizaban otras actividades de investigación y de transectos aleatorios grupo-pellet durante el periodo de primavera-otoño cuando, el ganado pastoreaba el hábitat de mayor elevación. La distribución del ganado difiere en diferentes variables del hábitat entre las bases de datos aunque, los modelos de distribución de ambas bases de datos indicaban la elevación, pendiente, distancia a los abrevaderos y caminos y cubierta vegetal que más influencian la presencia del ganado. La presencia del ganado fue asociada con una variedad de tipos de cubiertas y el ganado estuvo generalmente, a 500 metros del abrevadero y pendientes del 15-20\%. Modelos basados en observaciones mostraron una asociación positiva con los tipos de cubierta abiertos incluyendo una fuerte asociación positiva con las praderas montane que es el área de conflicto en el LNF. En contraste, los modelos basados en transectos mostraron una asociación positiva con mas tipos de cubiertas (11) que los basados en observaciones (6). Los modelos basados en observaciones mostraron mayor asociación con áreas cerca de los caminos. Preferencias de hábitat basadas en deducciones y observaciones casuales del ganado no pueden reflejar de manera precisa la verdadera distribución o uso de la misma forma que lo hacen los modelos basados en transectos que predicen de manera más amplia la distribución a través del LNF y mayores probabilidades en general de presencia de ganado. Debido a que la distribución del ganado incluye algunos otros tipos de cubierta vegetal en adición a las praderas montane el manejo que promueva una correlación positiva en la distribución del ganado en el LNF podría ser de utilidad el alterar la distribución del ganado fuera de las áreas donde se percibe que hay conflicto.

Key Words: cover, habitat use, high elevation, pellet transects

Current address: Heather Halbritter, Terrestrial Biologist, Northeast Region, Colorado Dept of Wildlife, 6060 Broadway, Denver, C0 80216, USA.

Correspondence: Louis C. Bender, Extension Animal Sciences and Natural Resources, New Mexico State University, PO Box 30003 MSC 3AE, Las Cruces, NM 88003, USA. Email: Ibender@nmsu.edu

Manuscript received 17 March 2010; manuscript accepted 10 May 2011.

\section{INTRODUCTION}

Real or perceived conflicts often exist with cattle use of western North American rangelands (Vavra 1992, 2005). Such a situation occurs on the Lincoln National Forest (LNF) in the southern Sacramento Mountains of south-central New Mexico, USA, where perceived overuse of montane meadow communities 
by cattle and elk (Cervus elaphus) has resulted in demands for reductions in one or both species to alleviate perceived conflicts (Wright 2000; Halbritter 2007). Consequently, numbers of cattle allowed on grazing allotments have been significantly reduced (Hurd 2002; Halbritter 2007). A frequently cited factor for reduction of cattle numbers was assumed preferential and deleterious use of montane meadows by cattle.

Habitats used by cattle presumably represent a resource selection process that allows individuals to best meet their life requisites in that area (Holechek et al. 2004; Bailey 2005). Included in this should be a balance of forage and cover areas that allows optimization of cow condition for the local habitat characteristics. Ranges of cattle are formulated by many factors, but cattle are frequently limited in habitats used because of limited mobility (Holechek 1988; Hart et al. 1993; Sheehy and Vavra 1996; Holechek et al. 2004; Bailey 2005). Knowledge of distribution patterns and key habitat correlates of cattle thus allows identification of management practices that facilitate preferred habitat components and thus potentially affect distribution (Bailey 2005), minimizing local conflicts.

To achieve this requires reliable knowledge of areas used by cattle and habitat correlates associated with these areas. Use of casual visual observations to derive conclusions regarding cattle distribution may not provide such knowledge because of a lack of sampling strategy. Consequently, management decisions based on observational data may be misinformed and therefore fail to achieve resource objectives. Because management decisions regarding cattle herbivory on LNF are primarily based upon assumed affinities of cattle for montane meadow communities, our goal was to determine cattle distribution in LNF and identify habitat correlates associated with cattle presence. Further, because much of what is assumed about cattle habitat use patterns is based upon casual observations, we also wanted to contrast models of cattle distribution and determine if habitat correlates differed between models based upon casual observations of cattle presence and randomized transect-based sampling strategies.

\section{METHODS}

\section{Study Area}

Our study area encompassed much of the Sacramento Ranger District of Lincoln National Forest, located in the Sacramento Mountains of south-central New Mexico (approximately $\left.32^{\circ} 49^{\prime} 59^{\prime \prime} \mathrm{N}, 105^{\circ} 43^{\prime} 01^{\prime \prime} \mathrm{W}\right)$. The Sacramento Ranger District manages 182278 ha of the Lincoln National Forest. Average high temperature in June is $23^{\circ} \mathrm{C}$ and average low January temperature is $-7^{\circ} \mathrm{C}$. Annual precipitation averages $67 \mathrm{~cm}$ with $>50 \%$ falling June-September. Annual snowfall averages $183 \mathrm{~cm}$.

Vegetation communities in the Sacramento Mountains are very diverse due to differences in elevation and precipitation. Desert scrub-grassland habitat covers the lower foothills from 1380 to $1830 \mathrm{~m}$ (Kaufmann et al. 1998). Pinyon-juniper (Pinus edulis Engelm./Juniperus monosperma [Engelm.] Sarg.) woodland occurs along with areas of dense Gambel oak (Quercus gambelii Nutt.) above 1700-1800 m, usually along canyons and ridges. Ponderosa pine ( $P$. ponderosa Doug. ex Laws.) is found above $2100 \mathrm{~m}$ typically mixed with pinyon-juniper or Douglas-fir
(Pseudotsuga menziesii [Mirb] Franco). Above 2200-2 500 m, the mountains are dominated by a mixed conifer forest, consisting of white fir (Abies concolor [Gord. \& Glend.] Lindl. ex Hildebr.), Douglas-fir, ponderosa pine, Southwestern white pine (P. strobiformis Engel.), and occasionally blue spruce (Picea pungens Engelm.) or Engelmann spruce (P. engelmannii Parry ex Engelm.). Pockets of aspen (Populus tremuloides Michx.) are found mixed within the conifers, rarely in pure stands. Montane meadows are numerous at high elevations.

During our study the Sacramento Ranger District managed 38 grazing allotments with 34 permittees. The majority of our study area was in the spring-autumn range of the Sacramento allotment, which encompassed approximately 44744 ha. In 2004-2006, approximately 330 permitted cattle grazed the allotment for a density of 0.7 cows $\cdot \mathrm{km}^{-2}$. Grazing followed a deferred rotation system from mid-May through October, with two pastures alternating annually between early summer (midMay through early August) and late summer (early August through late October) grazing. Each pasture was grazed by cattle during one of the periods each year, but not the same period in consecutive years.

\section{Cattle Presence}

We constructed a vegetation cover map from US Geological Survey Southwest Regional Gap Analysis (SWReGAP) vegetation classifications and US Forest Service vegetation cover maps. We reclassified the original 48 SWReGAP habitat types into 17 cover types that reflected the majority of vegetation communities of importance to cattle on LNF (Wright 2000; Hurd 2002). We added forest management practices (thinned stands, burns, etc.) derived from US Forest Service vegetation maps to the reclassified SWReGAP coverage. This resulted in a total of 28 vegetation cover types present in the study area.

We used observation and transect data as presence/absence data only for modeling cattle distribution (as contrasted with weighted count data). We recorded locations of all cattle observed (sensu Roath and Krueger 1982) during all field activities associated with a multiyear study of elk and cattle ecology on LNF (Halbritter 2007) with a handheld GPS unit and plotted locations using ArcGIS 9.1 (ESRI, Redlands, California, USA). We further recorded cattle presence by pellet-group transects, which are adequate to assess relative use among habitats (Cook 1966; Neff 1968), collected throughout the spring-autumn ranges of cattle in LNF. We conducted pellet surveys in April and August-September 2005 and 2006. For each sampling period, we randomly selected 40 55 replicate stands in cattle spring-autumn use areas based on expected cattle distribution in the montane habitats of LNF (Wright 2000; Hurd 2002). Stands sampled in AugustSeptember 2005 and April 2006 were unique to the two sampling periods, since they indexed use of the same season (spring-autumn 2005). We established a single 100-m transect per stand replicate, chose transect starting locations randomly, and each transect proceeded parallel to the longest dimension of the stand. We assessed cattle presence by counting pellet groups encountered within $2 \mathrm{~m}$ of a straight line, i.e., a $2 \times 100$-m belt transect. We used the starting point of transect as the location point for geographic analysis. We counted only the current season's (previous season's for April transects) fecal 
pats on surveys, which we differentiated by moisture content and consistency. Cattle fecal pats dried and completely deteriorated within $1 \mathrm{yr}$ in the montane habitats of LNF.

\section{Modeling Cattle Distribution}

We modeled habitat features associated with presence of cattle using Maximum Entropy 3.1 (MaxEnt; Phillips et al. 2006) to identify habitat attributes associated with areas of increased probability of use by cattle. Maximum entropy is a machine learning response that utilizes only known occurrences (i.e., presence data; observations of cattle or locations of transects with cattle fecals in our study) and compares habitat correlates at those occurrence sites to the same correlates at 10000 random locations, rather than with inferred absences such as collected from transect-based sampling strategies. Because it uses only presence data, MaxEnt thus eliminates the need for pseudo-absence data, which can bias species-habitat models (Gu and Swihart 2004) and thus provides a less biased alternative to other approaches that require the generation of known nonuse areas (discriminant analysis, logistic regression, etc.; Phillips et al. 2006; Baldwin and Bender 2008a, b). Consequently, maximum entropy modeling consistently outperforms other methods of modeling spatial distribution using nonrepeated sampling (Elith et al. 2006; Hernandez et al. 2006; Phillips et al. 2006).

We modeled six variables shown to affect cattle habitat use (Hart et al. 1993; Holechek et al. 2004; Bailey 2005), including elevation, vegetation cover type, distance to roads, distance to permanent water sources (including perennial streams and rivers, springs, ponds, and permanent water developments), slope, and aspect. We used GIS coverages at $30-\mathrm{m}$ resolution in ArcGIS 9.1 to characterize sites of cattle observations and transect locations with cattle fecals with regard to these attributes and develop input environmental layers for each variable for use in MaxEnt. We used MANOVA (Morrison 1990) to compare presence of cattle with respect to continuous variables (e.g., distance to roads, distance to water, elevation, and slope) and Fisher's exact tests (Zar 1996) to compare presence of cattle with respect to vegetation type and aspect between observation and transect data.

We modeled all possible 1-6 variable candidate models and compared resultant models using receiver operating characteristic (ROC) plots and the critical ratio test (Pearce and Ferrier 2000 as modified by Baldwin and Bender 2008a). We used ROC plots to assess relative performance and to establish thresholds for identifying the likelihood of a site being used by cattle (Phillips et al. 2006). The ROC is a plot of sensitivity and 1-specificity, with sensitivity representing how well the data correctly predict presence (cattle locations) while specificity provides a measure of correctly predicted random sites (Fielding and Bell 1997). We used the area under curve (AUC) to assist in selecting the most appropriate model (Fielding and Bell 1997; Phillips et al. 2006). This approach provides an index of model accuracy; values range from 0.5 to 1.0 with values of 0.5 indicating fit no greater than random, while models with AUC $>0.7$ indicate good fit (Swets 1988). We calculated standard errors for AUC values using 30\% of the locations as test data.

We compared all possible models and reported models with the highest AUC value for each subset of habitat variables (i.e.,
1-6 variable models). Because higher-dimensioned models often have greater AUC even if some variables contribute little to the final model (Baldwin and Bender 2008a), we (1) used AUC to select the model with the best fit (highest AUC) from each set of 1-6 variable models (to ensure that only models that fit the data well were considered) and then (2) compared whether higher dimensioned models differed statistically from more parsimonious models. If they did not differ, we selected the most parsimonious model as the best supported model. For the latter, we used the critical ratio test (Pearce and Ferrier 2000) to compare the most general model (containing all variables) to simpler models to determine if the increase in explanatory value was significant at $\alpha=0.05$ following Baldwin and Bender (2008a).

We also derived thresholds for probability of cattle presence for test data by maximizing sensitivity and minimizing specificity (Fielding and Bell 1997; Phillips et al. 2006) and compared probabilities of presence of cattle between final models using Fisher's exact test (Zar 1996). We used these thresholds to convert probabilities to binary response (presence-absence) and used the equal test sensitivity and specificity threshold values to calculate successful classification percentages to corroborate results from ROC curves. We corroborated selection of the best supported model using concordance (percent successful classification of use sites) because a model that poorly classifies the data it was built from is unlikely to have any true predictive ability (Hosmer and Lemeshow 1989). Last, we constructed response curves to illustrate the effect of significant variables on probability of a site being occupied by cattle. Upward trends for variables indicate a positive association, downward movements represent a negative relationship, and the magnitude of these movements indicates the strength of these relationships.

\section{RESULTS}

We recorded 902 observations of cattle and conducted 168 pellet-group transects, 2004-2006. Presence of cattle differed $\left(\mathrm{F}_{4,1} 065=17.4 ; P<0.001\right)$ between observation and transect occurrences with respect to distance from roads $\left(\mathrm{F}_{1,1068}=\right.$ $12.5 ; \quad P=0.004)$, distance from water $\left(\mathrm{F}_{1,1} 068=50.4\right.$; $P<0.0001)$, and elevation $\left(\mathrm{F}_{1,1068}=14.9 ; P<0.0001\right)$, but not slope $\left(\mathrm{F}_{1,1068}=0.9 ; P=0.345\right)$. Cattle presence also differed with respect to vegetation cover type (Fisher's exact $P<0.0001$ ) but not aspect (Fisher's exact $P=0.642$ ). Distribution data from observations indicated that cattle were seen closer to main roads ( $\overline{\mathrm{X}}=356 \mathrm{~m}[\mathrm{SE}=16]$ vs. $493 \mathrm{~m}[\mathrm{SE}=31])$ and water $(\overline{\mathrm{X}}=544 \mathrm{~m}[\mathrm{SE}=14]$ vs. $811 \mathrm{~m}[\mathrm{SE}=42]$, at slightly lower elevations $(\overline{\mathrm{X}}=2536 \mathrm{~m}[\mathrm{SE}=6]$ vs. $2602 \mathrm{~m}[\mathrm{SE}=17])$, and at similar slopes $(\overline{\mathrm{X}}=20.3 \% \quad[\mathrm{SE}=0.4]$ vs. $19.3 \%$ $[\mathrm{SE}=0.8])$ compared to transect-based distribution data. Cattle were detected in a similar number of vegetation cover types between methods (observation $=16$; transect $=17$ ), but types strongly positively or negatively associated with distribution varied between methods (Fig. 1).

\section{Cattle Distribution}

Cattle distribution was best predicted by elevation, vegetation cover type, distance to roads, distance to water, and slope, 
regardless of whether modeled from transect data or observation data (Table 1). Relationships among variables were generally similar for both models, with the exception of vegetation cover type relationships and proximity to roads (Figs. 1 and 2). Observation-based models indicated that cattle were most positively associated with montane meadows and desert grasslands, which were open habitat types where cattle were readily visible. In contrast, transect-based models indicated strongest positive association with montane oak shrubland and salvage logged areas and showed positive associations with more cover types (11) than did observationbased models (6; Fig. 1). Negative associations with cattle distribution similarly varied between models (Fig. 1). Modeled relationships between distance to roads and cattle distribution from observation data indicated that cattle were found in proximity to roads (Fig. 2), whereas relationships based on transect data indicated more uniform use by cattle as distance from roads increased (Fig. 2).

Both observation-based and transect-based models indicated (1) likelihood of cattle presence declined with increasing distance from water, with presence maximized within $500 \mathrm{~m}$ of water and essentially no presence occurring at $>3000 \mathrm{~m}$ from water; (2) likelihood of cattle presence increased with elevation, likely a response to earlier plant phenology state during spring-autumn; and (3) cattle presence decreased as slope increased, with associations greatest with slopes of $<10$ $15 \%$ (Fig. 2).

Primarily due to differences in associations among vegetation cover types and distance to roads relationships, the transectbased model predicted a greater proportion (Fisher's exact $P<0.0001$ ) of our study area with higher probability of cattle presence than did the observation-based model (Fig. 3). The proportion of our study area with $\leq 25 \%, 26-50 \%, 51-75 \%$, and $\geq 76 \%$ predicted probability of cattle presence was 0.446 , $0.370,0.172$, and 0.012 , respectively, for the transect-based model. The same proportions were $0.553,0.356,0.075$, and 0.016 for the observation-based model. Additionally, the transect-based model predicted that approximately 10 times more (proportion $=0.002$ vs. 0.0002 ) of our study area had a $\geq 90 \%$ probability of cattle presence.

\section{DISCUSSION}

Impressions of cattle distribution and habitat preferences are often based on casual visual observations of cattle, usually from roads, and these may not reflect true cattle-habitat relationships because of a lack of sampling strategy. Observation-based models indicated that cattle were far more likely to be located in open cover types in proximity to roads (Fig. 2) and that cattle had highest affinity for meadows or other open grasslands (Fig. 1). High use of riparian meadows (Cook 1966; Roath and Krueger 1982) and use of roads for movement (Roath and Krueger 1982) are common behaviors of cattle in forested mountainous ranges. However, because there was no randomization or other sampling strategy employed in observation-based models of cattle distribution in LNF, these results at least partially reflected bias in the collection method; observations most commonly occur along roads, roads go along or through most meadows in LNF, and large herbivores

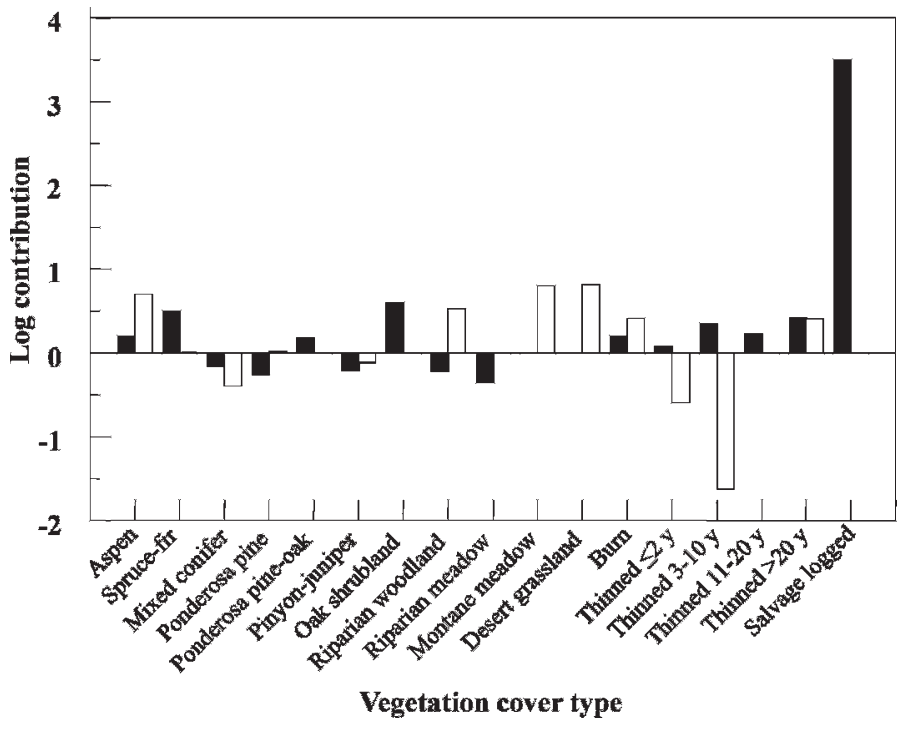

Figure 1. Relationships between cattle presence and vegetation cover type on Lincoln National Forest based on modeling of observation (open bars) and transect (solid bars) data. Cover type abbreviations: Thinned $\leq 2 \mathrm{yr}=$ thinned, no treatment defined, within last $2 \mathrm{yr}$; Thinned 3-10 $\mathrm{yr}=$ thinned, no treatment defined, from 3-10 yr previously; Thinned 11$20 \mathrm{yr}=$ thinned, no treatment defined, 11-20 yr previously; and Thinned $>20 \mathrm{yr}=$ thinned, no treatment defined, more than $21 \mathrm{yr}$ previously.

such as cattle are more readily observed in open habitats than in forested habitats (Thomas et al. 1979).

In contrast, randomly placed transects included more cover types of limited visibility and thus potentially allowed detection of cattle presence in areas used both for foraging (primarily open habitats) as well as other behaviors such as loafing or thermoregulation (primarily closed habitats; Holechek et al. 2004; Bailey 2005). Transects were also distributed independently of roads. Consequently, many impressions of cattle distribution, inferred habitat preferences, and impacts of cattle use on LNF habitats may have been based on flawed impressions of cattle habitat affinities derived from casual observations of cattle. For example, much of the conflict with cattle on LNF involves perceived overuse of montane meadows. However, grazing surveys conducted throughout the spring-autumn range of LNF (i.e., not just on meadows adjacent to roads, etc.) indicated that meadows were not overgrazed based on minimum residual stubble height recommendations (Halbritter 2007). Thus, conflicts on LNF were at least partially attributable to associations of cattle with meadows from observational sampling (Fig. 1).

In contrast to observation-based models, randomized transect-based data indicated a much broader distribution of cattle across the landscape, with much less affinity to open areas and areas immediately adjacent to roads (Fig. 3), again likely due to inclusion of vegetation cover types used for reasons other than feeding and watering. Consequently, while observation-based models indicated that montane meadows were strongly positively associated with cattle distribution in LNF, similar to findings in other forested mountainous ranges (Cook 1966; Roath and Krueger 1982), randomized transect-based models suggested that other vegetation cover types were also positively, 

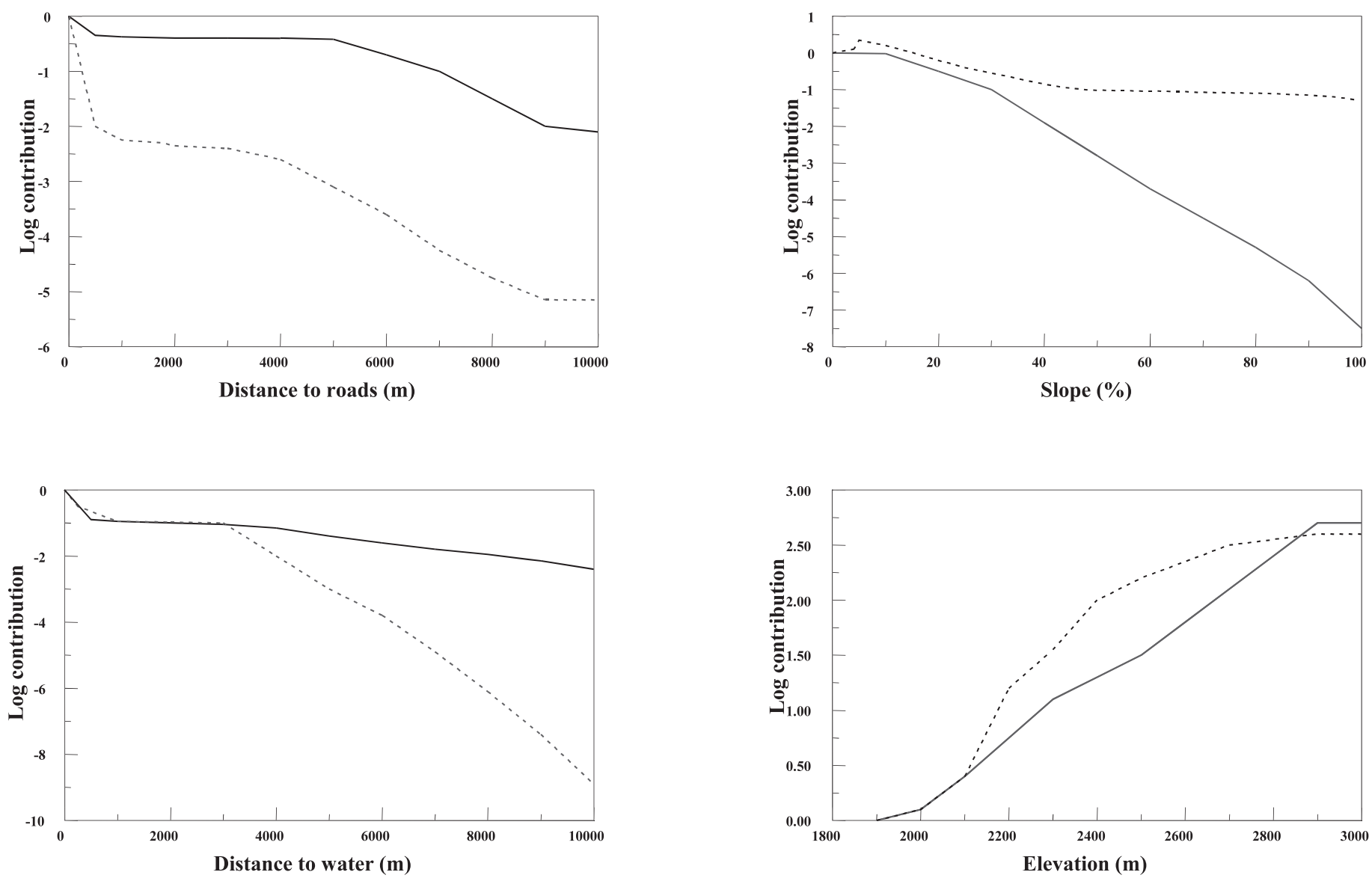

Figure 2. Relationships between cattle presence and distance to roads, distance to water, elevation, and slope on Lincoln National Forest based on modeling of observation (dashed lines) and transect (solid line) data.

and in some cases more strongly, associated with cattle presence in LNF (Fig. 1). These results support other information on cattle use of LNF habitats, where relative use (grazing) surveys showed high use of burns and thinned conifer as well as meadows by cattle (Halbritter 2007), with degree of use likely influenced by other key variables identified that affected cattle distribution (proximity to water, degree of slope, and elevation). Thus, cattle on LNF were much more flexible in habitats occupied than many believed, and this flexibility could potentially be used to address real or perceived problems

Table 1. Area under curve (AUC), Standard Error (SE), Z tests, associated probability $(P)$ between the model with the highest AUC and all other models, and corresponding classification percentages (Class \%) of models derived from maximum entropy modeling of cattle locations from transects and direct observations in Lincoln National Forest, 2003-2006. Best supported model is in boldface.

\begin{tabular}{|c|c|c|c|c|c|c|}
\hline Type & Model $^{1}$ & AUC & SE & $Z$ & $P$ & Class $\%$ \\
\hline \multirow[t]{5}{*}{ Transect } & Elev, veg, droads, dwater, slope, aspect & 0.774 & 0.025 & - & - & 86 \\
\hline & Elev, veg, droads, dwater, slope & 0.767 & 0.035 & 1.6 & 0.101 & 86 \\
\hline & Elev, veg, slope & 0.716 & 0.035 & 31.3 & $<0.001$ & 68 \\
\hline & Veg, elev & 0.740 & 0.037 & 17.1 & $<0.001$ & 61 \\
\hline & Elev & 0.695 & 0.048 & 40.9 & $<0.001$ & 60 \\
\hline & Veg, droads, dwater, slope & 0.799 & 0.020 & 104.0 & $<0.001$ & 79 \\
\hline & Elev, dwater, droads & 0.812 & 0.019 & 88.7 & $<0.001$ & 80 \\
\hline & Dwater, droads & 0.791 & 0.020 & 117.0 & $<0.001$ & 80 \\
\hline & Dwater & 0.702 & 0.029 & 177.9 & $<0.001$ & 77 \\
\hline
\end{tabular}

${ }^{1}$ Variable abbreviations: elev $=$ elevation, veg $=$ vegetation cover types, droads $=$ distance to roads, and dwater $=$ distance to water . 
a

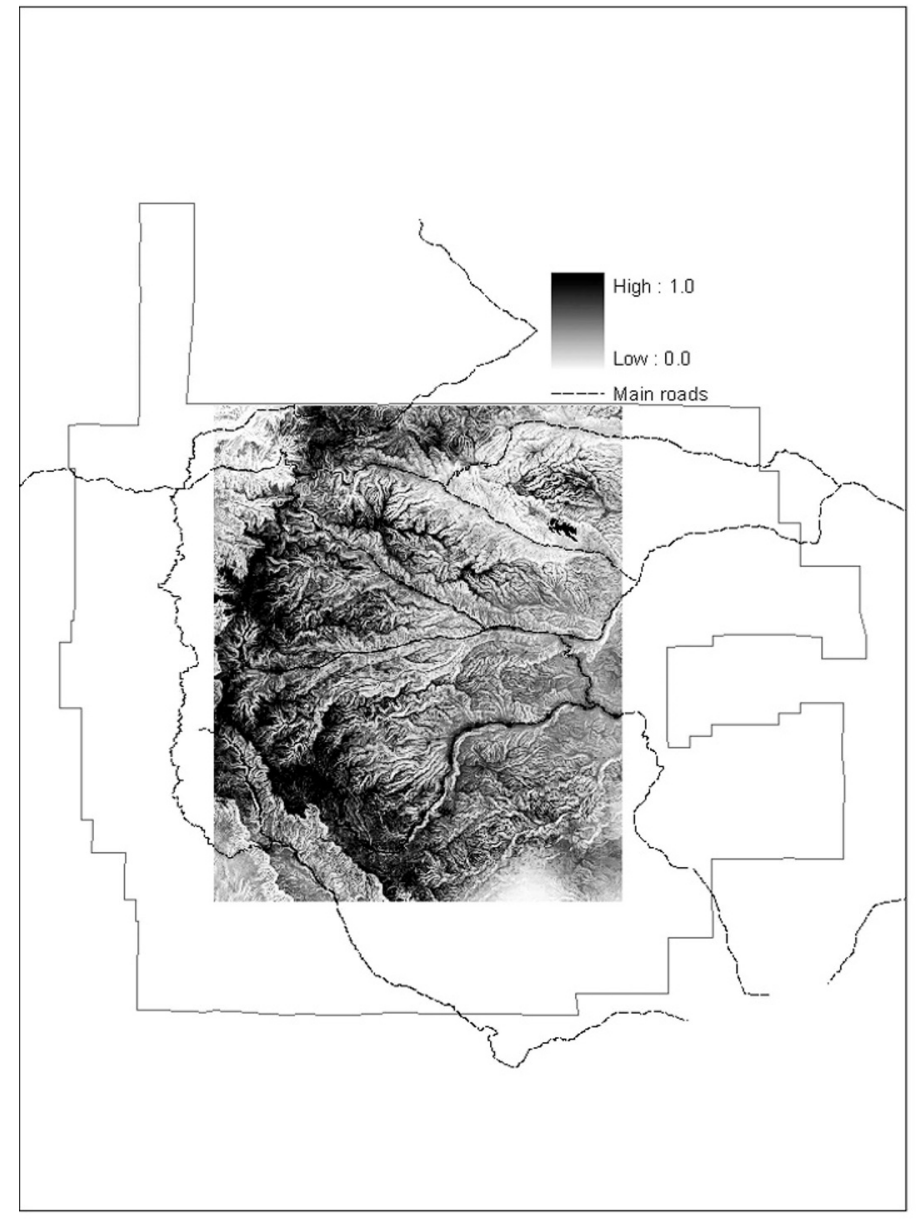

Transect b

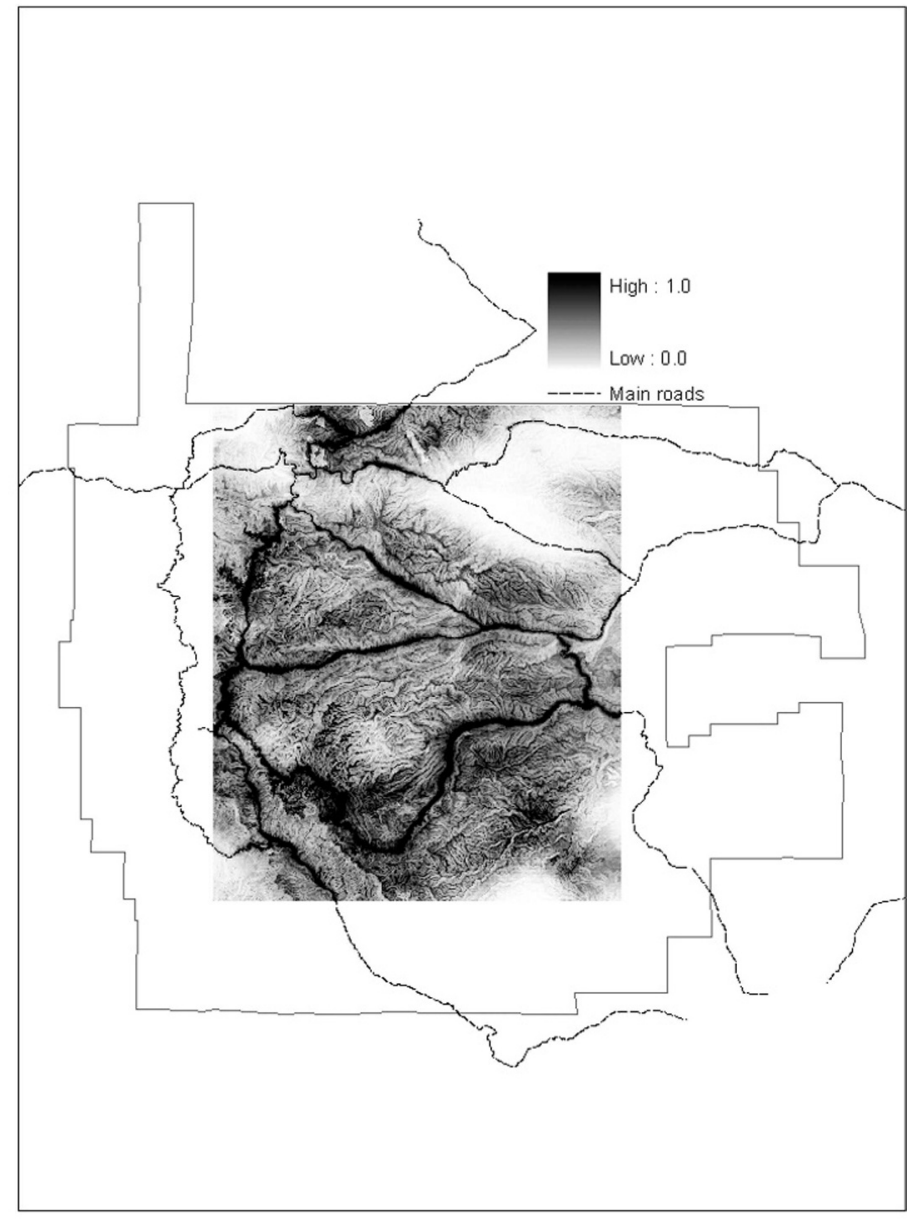

Observation

Figure 3. Probability of use of habitats by cattle in Lincoln National Forest as determined by modeling of cattle presence from transect data (a) and observation (b). Darker areas = higher probability of use.

associated with use of montane and riparian meadows on LNF (Bailey 2005). This was further illustrated by the higher overall potential of the LNF landscape for cattle as predicted by the transect-based model as compared to the observation-based one (Fig. 3).

Despite differences between observation and transect-based models with regard to cattle affinities for vegetation cover types and roads on LNF, both methods were similar with respect to other abiotic factors affecting cattle distribution. Similar to previous work on cattle in forested mountainous ranges, both models found cattle were most strongly associated with areas $<500$ m from water (Valentine 1947; Cook 1966; Roath and Krueger 1982; Gillen et al. 1984), although cattle showed a moderate probability of presence out to $3 \mathrm{~km}$ from water on LNF (Fig. 2), farther than data from other mountainous ranges would predict ( $2 \mathrm{~km}$; Roath and Krueger 1982). This may have been a result of not all ephemeral water sources being mapped on our study area, thus increasing apparent distance of cattle from water. Cattle were also strongly associated with slopes of $<15 \%$, again similar to previous work in forested mountain ranges that found use limited to slopes $<20-25 \%$ (Cook 1966; Gillen et al. 1984; Tortenson et al. 2006).

\section{MANAGEMENT IMPLICATIONS}

Management decisions should be based on rigorous, quantified data; recommendations based on qualitative observations of cattle may not accurately reflect true distribution or use by cattle. Cattle distribution patterns can be readily changed through management practices, and altering the distribution of cattle may have the ability to address the majority of resource concerns associated with grazing (Bailey 2005). Modeling of cattle presence on LNF indicated that cattle distribution was associated with, and thus presumably could be affected by, thinning conifer stands, prescribed burning, and water developments, especially if treatments were associated with slopes $<15 \%$ and were within $0.5-1 \mathrm{~km}$ of water or included water developments (Figs. 1 and 2). Although most conflict with cattle on LNF involves perceived overuse of montane meadows, this was likely attributable to associations of cattle with meadows from observational sampling (Fig. 1), as vegetation measures indicated that meadows were not overgrazed based on minimum residual stubble height recommendations (Halbritter 2007). Because cattle in fact used many other vegetation cover types on LNF in addition to meadows, management practices such as 
those noted above may be useful to alter cattle distribution away from areas of conflict, and thus relieve real or perceived pressure on meadow communities. Altering distribution may further result in more uniform use of LNF ranges (Bailey 2005), or more areas being used by grazing cattle than were previously used, thus increasing the grazing capacity of LNF for cattle while concurrently addressing the perceived grazing conflict.

\section{ACKNOWLEDGMENTS}

We thank the New Mexico Department of Game and Fish, US Forest Service, and the New Mexico State University, Agricultural Experiment Station, for funding this project. We thank B. Barrett, T. Kamienski, J. Piasecke, E. Watters, and M. Weisenberger for their contributions to this project. All activities were performed in accordance with NMSU Institutional Animal Use and Care Committee Permit No. 2003-023.

\section{LITERATURE CITED}

BAILEY, D. W. 2005. Identification and creation of optimum habitat condition for livestock. Rangeland Ecology \& Management 58:109-118.

Baldwin, R. A., And L. C. Bender. 2008a. Den-site characteristics of black bears in Rocky Mountain National Park, Colorado. Journal of Wildlife Management 72:1717-1724.

Baldwin, R. A., and L. C. Bender. 2008b. Distribution, occupancy and habitat correlates of American martens (Martes americana) in Rocky Mountain National Park, Colorado. Journal of Mammalogy 89:419-427.

Соoк, C. W. 1966. Factors affecting utilization of mountain slopes by cattle. Journal of Range Management 19:200-204.

Elith, J., C. H. Graham, R. P. Anderson, M. Dudik, S. Ferrier, A. Guisan, R. J. Hijmans, F. Huettmann, J. R. Leathwick, A. Lehmann, J. Li, L. G. Lohmann, B. A. Loiselle, G. Manion, C. Moritz, M. Nakamura, Y. Nakazawa, J. McC. Overton, A. T. Peterson, S. J. Phillips, K. S. Richardson, R. Scachetti-Pereira, R. E. Schapire, J. Soberón, S. Williams, M. S. Wisz, and N. E. Zimmermann. 2006. Novel methods improve prediction of species' distributions from occurrence data. Ecography 29: 129-151.

Fielding, A. H., And J. F. Bell. 1997. A review of methods for the assessment of prediction errors in conservation presence/absence models. Environmental Conservation 24:38-49.

Gillen, R. L., W. C. Krueger, and R. F. Miller. 1984. Cattle distribution on mountain rangeland in northeastern Oregon. Journal of Range Management 37: 549-553.

Gu, W., and R. K. Swihart. 2004. Absent or undetected? Effects of non-detection of species occurrence on wildlife-habitat models. Biological Conservation 116:195-203.

HalbritTER, H. 2007. Demographics, habitat use, and foraging by sympatric elk and cattle on Lincoln National Forest [thesis]. Las Cruces, NM, USA: New Mexico State University. 192 p.
Hart, R. H., J. Bisso, M. J. Samuel, and J. W. Waggoner JR. 1993. Grazing systems, pasture size and cattle grazing behavior, distribution and gains. Journal of Range Management 46:81-87.

Hernandez, P. A., C. H. Graham, L. L. Master, and D. L. Albert. 2006. The effect of sample size and species characteristics on performance of different species distribution modeling methods. Ecography 29:773-785.

HoleCHEK, J. L. 1988. An approach for setting the stocking rate. Rangelands 10:10-14

HolecheK, J. L., R. D. Pieper, and C. H. Herbel. 2004. Range management principles and practices. Englewood Cliffs, NJ, USA: Prentice Hall. 607 p.

Hosmer, D. W., AND S. LemeSHow. 1989. Applied logistic regression. New York, NY, USA: John Wiley and Sons. $307 \mathrm{p}$.

HuRD, B. J. 2002. Effects of big game and livestock on plant cover, composition, and herbaceous biomass in logged areas of the Sacramento Mountains [thesis]. Las Cruces, NM, USA: New Mexico State University. 105 p.

Kaufmann, M. R., L. S. Huckaby, C. M. Regan, and J. Popp. 1998. Forest reference conditions for ecosystem management in the Sacramento Mountains. Ft. Collins, CO, USA: US Forest Service General Technical Report RMRS-GTR-19. $87 \mathrm{p}$.

Morrison, D. F. 1990. Multivariate statistical methods. New York, NY, USA: McGraw-Hill. $495 \mathrm{p}$.

NefF, D. J. 1968. The pellet-group count technique for big game trend, census, and distribution: a review. Journal of Wildlife Management 32:597-614.

Pearce, J., and S. FerRier. 2000. Evaluating the predictive performance of habitat models developed using logistic regression. Ecological Modelling 133: 225-245.

Phillips, S. J., R. P. Anderson, and R. E. Schapire. 2006. Maximum entropy modeling of species geographic distributions. Ecological Modelling 190: 231-259.

Roath, L. R., and W. C. Krueger. 1982. Cattle grazing and behavior on a forested range. Journal of Range Management 35:332-338.

SheEHY, D., And M. Vavra. 1996. Ungulate foraging areas on seasonal rangeland in northeastern Oregon. Journal of Range Management 49:16-23.

SwETS, J. A. 1988. Measuring the accuracy of diagnostic systems. Science 240:1285-1293

Thomas, J. W., H. Black JR., R. J. Scherzinger, and R. J. Pedersen. 1979. Deer and elk. In: J. W. Thomas [ED.]. Wildlife habitats in managed forests: the Blue Mountains of Oregon and Washington. Portland, OR, USA: US Department of Agriculture Agricultural Handbook No. 553. p. 104-127.

Tortenson, W. L. F., J. C. Mosley, T. K. Brewer, M. W. Tess, and J. E. Knight. 2006. Elk, mule deer, and cattle foraging relationships on foothill and mountain rangeland. Rangeland Ecology \& Management 59:80-87.

Valentine, K. A. 1947. Distance from water as a factor in grazing capacity of rangeland. Journal of Forestry 45:749-754.

VaVRA, M. 1992. Livestock and big game forage relationships. Rangelands 14:57-59.

Vavra, M. 2005. Livestock grazing and wildlife: developing compatibilities. Rangeland Ecology \& Management 58:128-134.

WRIGHT, B. D. 2000. Ungulate distribution and forage utilization in the Sacramento Mountains [dissertation]. Las Cruces, NM, USA: New Mexico State University. $74 \mathrm{p}$.

ZaR, J. H. 1996. Biostatistical analysis. 3rd ed. Upper Saddle River, NJ, USA: Prentice Hall. 662 p.+ app. 